\title{
Mapping and Deployment of Blast Resistance Gene in Rice - A Work in Progress
}

\author{
Ashim Debnath", Karma Landup Bhutia and Hage Sumpi \\ School of Crop improvement, College of Post Graduate Studies, Central Agricultural \\ University (Imphal), Umiam, Pin: 793103, Meghalaya, India \\ *Corresponding author
}

\section{A B S T R A C T}

Rice (Oryza sativa) plays a significant role in global food security. Various biotic and

\section{Keywords}

Blast (Magnaporthe

oryzae), Resistance

genes, Quantitative trait

loci, Cloned genes,

Marker assisted selection

Article Info

Accepted:

16 April 2018

Available Online:

10 May 2018 abiotic stresses limit rice production. Among the various biotic stress, rice blast caused by Magnaporthe oryza is one of the most ruinous disease in all rice growing regions of the world. Use of resistant genes and quantitative resistance conferred by quantitative trait loci (QTLs) is the best option for management of blast. More than 100 blast resistance genes and a large number of QTLs (more than 350) were identified and mapped in different rice genotypes, but only 22 genes have been cloned and characterized at the molecular level. The genetic dissection of cloned genes revealed that the largest class of R-genes encodes nucleotide-binding, leucine-rich repeat (NBS-LRR) proteins. Gene pyramiding with marker assisted selection helps us to introgress more than one gene for blast resistance into a susceptible background. In this review, we extensively summarize the reported resistance gene information for rice blast along with their selection markers. We also focus on the reports of mapping and deployment of blast resistance with MAS and gene pyramiding. This update information will be helpful in rice breeding programmes to develop durable blast resistant rice variety through marker assisted selection.

\section{Introduction}

Rice (Oryza sativa) is one of the major foods for more than $50 \%$ of the world's population. The rice consumer is increasing and demand for rice is also moving up at an alarming rate. Rice production needs to increase more than $40 \%$ by 2030 to meet the increase demand for rice (Kush, 2005). The yield potentiality of rice is 10 ton $^{-1}$, whereas farmers on an average harvest about 5 ton $^{-1}$ (Kush and Jena, 2009). Various biotic and abiotic stress limit rice production which ultimately leads to this yield difference. Among the biotic stress, rice blast caused by Magnaporthe oryzae ranked first in the ten most important fungal pathogen explained in the journal of Molecular Plant Pathology. The economic importance of $M$. oryzae; with over one-half of the world's population relying on rice as the main source of calories, this pathogen can have destructive effects; however this pathogen has evolved into a seminal model system for the study of plant-pathogen interactions (Dean et al., 2012). The pathogen is most usual on leaves, causing leaf blast during the vegetative stage, 
or on nodes, neck and panicle branches during the reproductive stage, causing node and neck blast, respectively. The amount of rice destroyed by blast annually is sufficient to give food to 60 million people worldwide (Parker et al., 2008). Leaf blast lesions decrease the net photosynthetic rate of individual leaves to an extent far beyond the visible diseased leaf fraction. Neck blast is considered the most destructive phase of the disease and can occur without being introduced by severe leaf blast (Zhu et al., 2005). Neck blast causes direct yield reduction, since filling of the grains on infected panicles is poor at best. That is why neck blast is the more serious phase of the blast disease (Khan et al., 2014).

Different fungicides can be used to control blast disease but they generate additional costs in rice production and chemical contamination of environment and food items. Therefore strategies for increase in yield in an environmentally sustainable and economical manner need to be implemented urgently. Although host resistance is the most economically viable and environmentally sustainable practice to manage blast disease, the fungus overcomes blast resistance quickly, and cultivars typically become susceptible to disease within 2-3 years. Knowledge of the biology, adaptability and genetic diversity of the blast pathogen is vital for the development of novel and durable strategies to manage this and related devastating fungal diseases. The use of resistant varieties is thought to be one of the most economical and environment friendly ways of crop protection from the disease. The pyramiding of resistant genes or allocate them with multigenic resistance is an efficient way to manage blast disease. Accordingly, different molecular techniques such as QTL analysis, molecular mapping, gene cloning, map-based cloning, markerassisted selection (MAS) have been introduced to analyse the blast resistant genes in the rice genome (Miah et al., 2013). With a shorter period of time MAS offer better selection strategies in rice breeding.MAS are more efficient, effective and reliable as compare with phenotypic selection. Although MAS is not the only solution of all problem in resistance breeding but it is a promising approach to conventional breeding. Considerable progress has been done for rice blast disease towards cloning and identification of resistance genes, characterization of defense responses and elucidation of signal transduction which ultimately activate different defense responses. MAS help in transferring blast resistance genes to different genetic backgrounds at an early stage with greater accuracy (Gu et al., 2005). The ability to conduct genetic analyses led to the cloning and characterization of several genes for host and cultivar specificity. Today, much attention is given on cloning and characterizing many avirulence and corresponding rice resistance genes that have been genetically identified. Development of broad spectrum and durable blast resistant varieties is essential for combating this devastating disease, which requires continuous efforts of breeders and pathologists. Wild species of Oryza can be utilized to widen the gene pool of rice for biotic and abiotic stress. Various studies have demonstrated that wild species serve as a source of hidden gene(s) which can be used for crop improvement (Zhang and Xie, 2014) and yield enhancing QTLs from various wild species (Linh et al., 2008; Rangel et al., 2008).

\section{Blast resistance genes and sources}

The genus Oryza consists of two cultivated and 21 wild species. Two cultivated species, O. sativa and $O$. glaberrima, and six wild species, $O$. rufipogon, $O$. nivara, $O$. glumaepatula, $O$. meridionalis, $O$. breviligulata, and $O$. longistaminata have 
been grouped into a primary gene pool based on the transfer ability of genes (Sharma et al., 2012). Rice has domesticated almost 9000 years ago and during the period of domestication rice plant has been subjected to selection both by naturally and artificially which ultimately led to the reduction of diversity in the present rice species. Human selection process favoured the agronomically suitable characters over those of less cultivated species and wild relatives. This selection process for long period of time lead to more uniformity in the cultivated rice lines than wild relatives and land races. So the genetic base has been narrowed down due to the more uniformity in the cultivated rice which ultimately helps plant pathogen for better survival. The large source of genetic pool, land races and some cultivated rice germplasms were left unexplored.

In rice breeding, breeders have successfully taken many genes from wild species for useful trait like blast resistance. Wild rice, $O$. rufipogon has been reported to be a potential source for blast resistance genes (Rathour et al., 2005). Ram et al., (2007) reported the introgression of broad spectrum blast resistance gene(s) from Oryza rufipogon into indica rice cultivar. Blast resistance gene $\mathrm{Pi9}$ from Oryza minuta (Sharma et al., 2012), Pirf2-1(t) from wild rice $O$. rufipogon (Dwinita et al., 2008) and Pi-40(t) from Oryza eaustraliensis (Jeung et al., 2007) also been isolated. After considering the vast genetic diversity of rice, there is still so much potential to use the rice germplasm for the improvement of traits like blast resistance.

Rice blast disease resistance genes were first described in 1923 by Sasaki in Japan. Pi-a, the first blast resistance gene in rice was designated by Kiyosawa (Kiyosawa, 1966). Till now more than 100 blast resistance gene has been identified and their chromosomal locations and selection markers have been reported in different rice cultivars. Of the 100 blast resistance genes identified, these genes have different origins, and each was identified in different donor rice cultivars and also in wild rice species (Table 1). Out of the total identified resistance genes, $45 \%$ are from Japonica cultivars, and $51 \%$ from indica cultivars and the remaining $4 \%$ are from wild species of rice (Sharma et al.,2012).

From the tabular representation (Table 1) of different blast resistance gene, we can clearly observe that most of the $\mathrm{R}$ genes were detected on chromosome 11, 12 and 6 . Chromosome 11, with the maximum number of resistance genes, with at least 30 genes and alleles (Pik-h, Pi-hk1, Pi54, Pi-1(t), Pb1, Pise1, Pikur2, Pi 38, Pik,Pif, Pi34, Pia, Mpiz, Piisi, PiCO39(t), Pilm2, Pi30(t), Pi7(t), Pi44(t), Pi49, Pik-m, Pik-p, Pik-s, Pi47, Pikg, Pi60(t), Pi-1(t), Pi1 and PBR), chromosome 12 have atleast 23 number of resistance genes and alleles (Pi24(t), Pi-42(t), Pi51(t), Pi62(t), Pi6(t), Pi12(t), Pi4(t), Pi32(t),Pi31(t), Ipi(t), IPi3(t),Pita-2, Pi19(t), Pi21(t), Pita, Pi58(t), Pi39(t)，Pi-GD-3(t)，Pi20(t)，Pi-tq6，Pi48， Pi61(t), Pi157) and chromosome 6 have19 number of genes and alleles $(\operatorname{Pigm}(\mathrm{t}), \operatorname{Pi} 22(\mathrm{t})$, Pi26, Pi27(t), Piz-5, Pi8, Pi13(t), Pi40(t), Pi59(t), Pi9, Pi2-2, Pi50(t)).Although numbers are less but $\mathrm{R}$ genes were also detected for blast resistance in all other chromosomes except chromosome number 3 .

\section{QTL mapping for blast resistance in rice}

Disease resistance traits are controlled by many genes which are known as polygenes or quantitative trait loci (QTLs). Molecular marker such as RFLP, AFLP, SSR, SNP and EST are commonly used to map QTLs (Langridge et al., 2001). Basically there are four approaches for QTL mapping such as single marker analysis (SMA), simple or standard interval mapping (SIM), composite interval mapping (CIM) and multiple interval 
mapping (MIM). SMA method has been used for the first time in the identification of QTLs for rice blast resistance in cv. Moroberekan, a Japonica rice cultivar (Wang et al., 1994). In SMA method on the basis of the genotype at every marker locus, the mapping population is divided into classes and finally the QTL has been distinguish if significant differences in the overall mean phenotypic score are found for every group (Melchinger et al.,1998). SIM method is more efficient than SMA where at each locus; a flanking marker is used between two marker intervals. The main disadvantage of SIM is the identification of sometimes false QTLs because of linked and unlinked QTLs. Standard interval mapping was used for QTL analysis and mapping of blast resistance gene pi21 in Owarihatamochi, a Japanese upland rice cultivar (Fukuoka and Okuno, 2001).

The third approach, the composite interval mapping, is frequently used. Here, subsets of markers are used at both linked and unlinked QTLs. The CIM method is used for the identification of interaction of QTLs and marker information increase the power of QTL detection. The fourth approach, multiple interval mapping has higher precision for determining the combined effects of individual QTLs. To map the QTLs, multiple marker intervals are used in MIM method to fit various putative QTLs directly into the model.

More than 350 QTLs for leaf blast resistance have been mapped on different chromosomes, which are mainly derived from japonica indica crosses of 15 different populations (Wu et al., 2005; Ballini et al., 2008). The 23 blast resistance loci found within the above mentioned QTL regions are $\mathrm{Pi} 24(\mathrm{t}), \operatorname{Pi} 35(\mathrm{t})$, Pitq5, Pi25(t), pi21, Pi26(t), Pi27(t), Pi25(t), Pitq1, Pizh, Pi29(t), PiGD-1(t), Pi28(t), PiGD2(t), Pilm2, Pi30(t), Pi7(t), Pi34,Pi24(t), Pitq6, Pi31 $(\mathrm{t}), \quad$ Pi32(t), PiGD-3(t) (Fukuoka et al.,2014).

\section{Molecular mapping of blast resistance genes}

By crossing a japonica variety (Nipponbare) with an indica variety (Kasalath) a population of $186 \mathrm{~F}_{2}$ individuals was generated which was used for the construction of rice genetic map. With the use of Restriction Fragment Length Polymorphism (RFLP) markers, construction of the rice genetic map started in 1997 and further saturation of RFLP mapping was done by using RAPD and SSR markers (Tanweer et al., 2015).

The molecular mapping of blast resistance genes is a most direct and convenient approach for the identification of blast resistance in the rice genome. Through molecular mapping major blast resistance genes and Quantitative Trait Loci (QTL) linked to blast resistance have been localized. The traditional African variety Moroberekan, with durable resistance against various pathotypes of $M$. oryzae, has been used as a donor for blast resistance in many breeding programmes.

An in silico approach which uses computional methods for identification of candidate genes. Here for genome wide comparison, the available sequences of two or more genomes are used (Shang et al., 2009). Gene prediction programs like, FGENESH and Rice GASS (using rice genome sequence of the prescribed size of fragment) are used for the identification of candidate genes.

For the verification of a true candidate, PCRbased markers are developed and used as cosegregation markers to screen blast resistant and susceptible varieties. This in silico approach has been successfully applied to identify blast resistance genes such as Pid3, Pik-p and Pi37, Pi25 (Hayashi et al., 2006; Lin et al., 2007; Shang et al., 2009; Chen et al., 2011). 
Molecular map based approach which is the most directed approach for the identification of resistance gene. This strategy has been used for identification of 30 blast resistance genes namely; Pit, Pi27(t), Pish, Pid1(t), Pig(t), Piy(t), Piy2(t), Pi39(t), Pi10, Pi40(t), Piz, Pigm(t), Pi33, Pi5(t), Pi15, PiCO39(t), Pi38, PBR, Pb1, Pi-kh, Pi1, Pik-m, Pik, Pik-p, Pik-s, Pi62(t), Pi157, Pita-2, Pi39(t), and Pi20(t) (Das et al.,2012).

Marker density in the rice genome has been increased to one marker per $\mathrm{cM}$ (on an average) because of development of highdensity linkage map in the USA and Japan (McCouch et al., 2002).

In India identification and cloning of blast resistance genes began in 2002 when rice line Tetep was found to be highly resistant for most of the strains of M. oryzae (Sharma et al., 2002).

Blast resistance gene Pitp $(\mathrm{t})$ has been mapped in cultivar Tetep by using simple sequence length polymorphism markers (Barman et al.,2004). Because of the huge potential of Tetep in resistance breeding for the effective management of rice blast in the NorthWestern region of India, the Pi-kh (Pi54) gene was mapped in the same cultivar Tetep using different types of DNA markers (Sharma et al., 2005).

Subsequently, Pi38 was identified in indica rice Tadukan (Gowda et al., 2006) and Pi42(t) from aindica cultivar DHR9 by Kumar et al., 2010. The Pi-kh (Pi54) gene is now being introgressed in Indian cultivars of rice using marker assisted back cross breeding because of its effectiveness against many strains of $M$. oryzae and availability of closely linked and also gene based markers (Singh et al.,2011).

The genetic dissection based on the mapping of blast resistance genes on different chromosomes showed that majority of these genes are made up of nucleotide binding siteleucine-rich repeat (NBS-LRR) domain (Monosi et al., 2004).

\section{Molecular cloning and characterization of blast $\mathbf{R}$ genes}

This is the most effective and direct approach towards understanding the structure and function of blast resistance genes. Although, more than 100 blast resistance genes have been identified and mapped, only $22 \mathrm{R}$-genes have been cloned and characterized at molecular level (Ashkani et al., 2014). The cloned resistance genes are scattered throughout eight (Chromosomes number 1, 2, 4, 6, 8, 9, 11 and 12) rice chromosomes. Distribution on the chromosomes (Table 2) shows that majority of the cloned genes are spotted on chromosome 11 (36\%) followed by chromosome $6(27.5 \%)$, chromosome 1 (14\%) and chromosome 2, 4, 8, 9 and 12 (each $4.5 \%)$.

The genetic dissection of cloned genes revealed that the largest class of R-genes (Class 1) encodes nucleotide-binding, leucinerich repeat (NBS-LRR) proteins, except Pid-2, which contains the receptor kinase domain. The NBS-LRR proteins are further subdivided into the Toll/interleukin 1 receptor (TIR) and coiled-coil (CC) groups based on the $\mathrm{N}$ terminal domain.

Out of these two types, only (CC)-NBS-LRR class proteins are found in monocots (Ashkani et al., 2014). As showed in the table among 22 cloned blast resistance genes, 13 genes fall into a category of CC-NBS-LRR type domain, eight into NBS-LRR proteins while Pid-2 possesses a unique type of protein called Blectin receptor which is having a serine threonine kinase type domain. For cloning most of the genes, map-based cloning strategy has been used. 
Table.1 List of identified blast resistance genes on rice chromosomes with necessary information

\begin{tabular}{|c|c|c|c|c|c|}
\hline $\begin{array}{l}\text { Gene } \\
\text { Symbol }\end{array}$ & $\begin{array}{l}\text { Chr. } \\
\text { number }\end{array}$ & Position(bp) & Marker name & Donar rice variety & References \\
\hline Pit & 1 & $2270216-3043185$ & $\mathrm{t} 311, \mathrm{t} 256, \mathrm{t} 8042$ & Tjahaja & Hayashi et al.,2006 \\
\hline Pitp(t) & 1 & $25135400-28667306$ & RM246 & CO39 and Tetep & $\begin{array}{l}\text { Wongsaprom et al.,2010; Barman et al., } \\
2004\end{array}$ \\
\hline Pi37 & 1 & $33110281-33489931$ & $\begin{array}{l}\text { RM302, RM212, FPSM1, } \\
\text { FPSM2,FPSM4, }\end{array}$ & Cultivar St. No. 1 & Lin et al.,2007 \\
\hline $\mathbf{P i 3 5}(\mathrm{t})$ & 1 & $33000000-34150000$ & RM1216, RM1003 & Hokkai 188 & $\begin{array}{l}\text { Barman et al.,2004 } \\
\text { Nguyen et al.,2006 }\end{array}$ \\
\hline Pi24(t) & 1 & $5242654-5556378$ & K5 & Azucena & Nguyen et al.,2006 \\
\hline Pi27 & 1 & $6230045-6976491$ & RM151, RM259 & Q14 and Q61 & Sallaudet al.,2003 \\
\hline Pish & 1 & & & Shin 2 & Zhu et al.,2004 \\
\hline Pi64 & 1 & & RM 11715, RM 11787 & Japonica landrace Yangmaogu (YMG) & Ma et al., 2015 \\
\hline Pid1(t) & 2 & $21875000-22475000$ & RM262 & $\begin{array}{l}\text { Lijiangxin-tuan-heigu (LTH) and } \\
\text { Jiangnanxiangnuo (JNXN) crossed } \\
\text { with Digu }\end{array}$ & Chen et al.,2004 \\
\hline Pi-y1(t) & 2 & $38300000-38525000$ & RM3248, RM20 & $\begin{array}{l}\text { Lijiangxin-tuan-heigu (LTH) and } \\
\text { Yanxian No.1 }\end{array}$ & Fukutaet al.,2004; Lei et al.,2005 \\
\hline Pi-Da(t) & 2 & & RM5529, RM211 & Dacca6 & Lei et al.,2005 \\
\hline Piy2(t) & 2 & $38300000-38525001$ & RM3248, RM20 & Yanxian No.1 & Fukutaet al.,2004; Lei et al.,2005 \\
\hline $\operatorname{Pig}(t)$ & 2 & $34346727-35135783$ & RM166, RM208 & Guangchangzhan & Shi et al.,2012; Zhu et al., 2004 \\
\hline $\operatorname{Pi25}(\mathrm{t})$ & 2 & $34360810-37725160$ & RG520 & IR64 & Wu et al.,1993; Nguyen et al.,2006 \\
\hline Pi-tq5 & 2 & $37625000-39475000$ & $\begin{array}{l}\text { RG520, RZ446b, RZ446a, } \\
\text { RG654,RG256 }\end{array}$ & Teqing & Tabienet al.,2002; Zhou et al.,2004 \\
\hline Pi14(t) & 2 & $1-6725831$ & Amp-1 & Maowang & Pan et al.,1996; Tabien et al.,2000 \\
\hline Pi-b & 2 & $38300000-38525000$ & b213, b28, b2, b3989 & BL1/Koshihikari & Wang et al.,1999; Hayashi et al.,2006 \\
\hline Pil6(t) & 2 & $1-6725831$ & Amp-1 & Maowang & Pan et al., 1997 \\
\hline pi21 & 4 & $5242654-5556378$ & P702D03_79 & Owarihatamochi & Ahn et al.,1997; Pan et al.,1998 \\
\hline Pikur1 & 4 & $24611955-33558479$ & & Kuroka & Fukuoka et al.,2007 \\
\hline $\mathbf{P i 3 9}(\mathbf{t})$ & 4 & $26850000-27050000$ & RM3843, RM5473 & Mineasahi and Chubu 111 & Liu et al.,2007 \\
\hline $\mathbf{P i}(\mathbf{t})$ & 4 & $2270216-3043185$ & & P167 (I) & Causse et al., 1994 \\
\hline Pi23 & 5 & $10755867-19175845$ & & Suweon 365 & Terashima et al.,2008 \\
\hline$\overline{P i 26(t)}$ & 5 & $8751256-11676579$ & RG313 & Azucena/Gumei 2 & $\begin{array}{l}\text { Wu et al.,1993; Ahn et al.,1996; } \\
\text { Nguyen et al.,2006 }\end{array}$ \\
\hline Pil0 & 5 & 14521809-18854305 & OPF62700 & Tongil & Wu et al., 2005 \\
\hline $\operatorname{Pigm}(t)$ & 6 & $10367751-10421545$ & C26348, S47656 & Gumei4 & Deng et al.,2006 \\
\hline
\end{tabular}




\begin{tabular}{|c|c|c|c|c|c|}
\hline $\operatorname{Pi22(t)}$ & 6 & $4897048-6023472$ & & Sweon 365 & Terashima et al.,2008 \\
\hline Pi26 & 6 & $8751256-11676579$ & K17, R2123 & Zhong 156/Gumei 2 & Wu et al.,2005 \\
\hline Pi27(t) & 6 & $5556378-744329$ & Est-2 & IR64 & Nguyen et al.,2006 \\
\hline Piz-5 & 6 & & BS2-Pi9 and NBS4-Pi9 & C101A51_CO39 & Deng et al.,2006 \\
\hline Pi8 & 6 & & Amp-3, pgi-2 & Kasalath & Tabien et al.,2000 \\
\hline $\operatorname{Pi13}(t)$ & 6 & & Amp-3 & Maowangu & Pan et al., 1996 \\
\hline Pi40(t) & 6 & $16274830-17531111$ & RM3330, RM527, S2539 & Co39 and IR50 cross with IR65482-4- & Jeung et al.,2007 \\
\hline Pi59(t) & 6 & & RM19835 & Haoru_US-2 & Zhou et al.,2006 \\
\hline Pi9 & 6 & $10386510-10389466$ & Nbs2-Pi9 and Nbs3-Pi9 & Cultivar TP309 & $\begin{array}{l}\text { Qu et al.,2006 } \\
\text { Koide } \text { et al.,2013 }\end{array}$ \\
\hline Pi2-1 & 6 & & AP4791 and AP4007 & Tianjingyeshengdao & Quet al.,2006 \\
\hline Pi-tq1 & 6 & & RZ682, C236, RG653, RZ508 & Teqing & Zhou et al.,2004 \\
\hline Piz-t & 6 & 14675000 & $\begin{array}{l}\text { z4794, z60510, z5765, zt56591, } \\
\text { zt5659 }\end{array}$ & $\begin{array}{l}\text { Isogenic line C101A51 and cultivar } \\
\text { CO39 }\end{array}$ & Hayashi et al.,2006; Deng et al.,2006 \\
\hline Pid2 & 6 & $17159337-17163868$ & CAPS 1 and CAPS 8 & Digu and Lijiangxin-tuan-heigu & Chen et al.,2006 \\
\hline $\operatorname{Pi25}(t)$ & 6 & $18080056-19257588$ & A7-RG456 & Zhong 156/Gumei 2 & Ahnet al., 1996 \\
\hline Piz & 6 & $10155975-10517612$ & $\begin{array}{l}\text { z4794, z60510, z5765, z56592, } \\
\text { z565962 }\end{array}$ & Zenith & Hayashi et al.,2006; Wang et al.,2012 \\
\hline Pi13 & 6 & & R2123, R538 & Kasalath & $\begin{array}{l}\text { Fjellstrom et al.,2006; Hayasaka et } \\
\text { al.,1995 }\end{array}$ \\
\hline Pi2-2 & 6 & & AP5659-3 and RM19817 & Jefferson & Ballini et al.,2008 \\
\hline Pi50(t) & 6 & & GDAP51 and GDAP16 & $\begin{array}{l}\text { EBZ x LTH F2 and (EBZ x LTH) x } \\
\text { LTH, BC1F2 }\end{array}$ & Jiang et al., 2012 \\
\hline Pil7(t) & 7 & $22250443-24995083$ & & Kasalath & Zhu et al.,2012 \\
\hline Pi33 & 8 & $5915858-6152906$ & RM72, RM44 & IR64_Azucena and Azucena_Bala & Berruyer et al., 2003 \\
\hline Pizh & 8 & $4372113-21012219$ & RZ617 & JX17_ZYQ8 & Sallaud et al.,2003 \\
\hline Pi36 & 8 & $2870061-2884353$ & RM5647, CRG2, CRG3, CRG4 & Q61 (I) & Liu et al.,2007 \\
\hline Pi29(t) & 8 & $9664057-16241105$ & RZ617, RGA-IR86 & IR64 & Nguyen et al.,2006 \\
\hline pi55(t) & 8 & & $\mathrm{H} 2$ and $\mathrm{H} 66$ & Yuejingsimiao 2 (YJ2) & Liu et al., 2005 \\
\hline PiGD-1(t) & 8 & & Oxsalate oxidase & Sanhuangzhan2 & He et al.,2012 \\
\hline Pi15 & 9 & $9641358-9685993$ & $\begin{array}{l}\text { BAPi15486,BAPi15782 and } \\
\text { BAPi15844 }\end{array}$ & Q61 and GA25 & Liu et al.,2004 \\
\hline Pi2(t) & 9 & $1022662-7222779$ & & Ishikari shiroke & Pan et al.,2003 \\
\hline $\mathbf{P i 3}(\mathrm{t})$ & 9 & $7825000-8250001$ & & Pai-kan-tao & Kinoshita \&Kiyosawa, 1997 \\
\hline $\operatorname{Pi5}(t)$ & 9 & $7825000-8250000$ & 94A20r, 76B14f, 40N23r & RIL260 (Moroberekan) & Kwon et al.,2008 \\
\hline Pi56(t) & 9 & & $\begin{array}{l}\text { CRG4 (CRG4-1 and CRG4-2) } \\
\text { and CRG5, and one SSR marker } \\
\text { RM24022 }\end{array}$ & SHZ-2 and BC-10 x TXZ-13 & Jeon et al., 2003 \\
\hline
\end{tabular}




\begin{tabular}{|c|c|c|c|c|c|}
\hline Pii & 9 & 2291804-28431560 & & Ishikari Shiroke (J) & Ise et al., 1991 \\
\hline Pi28(t) & 10 & $19565132-22667948$ & RZ500 & Azucena & Nguyen et al.,2006 \\
\hline PiGD-2(t) & 10 & & r16 & $\begin{array}{l}\text { Sanhuangzhan } 2 \text { x Lijiangxin-tuan- } \\
\text { heigu }\end{array}$ & He et al., 2012 \\
\hline Pik-h & 11 & 24761902-24762922 & $\begin{array}{l}\text { RM144, RM224, RM1233, } \\
\text { RM144, }\end{array}$ & HP2216 and Tetep & $\begin{array}{l}\text { Fjellstrom et al.,2004;Sharma et al., } \\
2005\end{array}$ \\
\hline Pi-hk1 & 11 & & RM27248 and RM27318 & Heikezijing & Liu et al.,2012 \\
\hline Pi54 & 11 & & TRS26, TRS33,RM2191 & Tetep & Wu et al.,2013 \\
\hline Pi-1(t) & 11 & & RM1233I and RM224 & $\begin{array}{l}\text { Near-isogenic lines C101LAC and } \\
\text { C101A5 }\end{array}$ & Sharma et al.,2005 \\
\hline $\mathbf{P b 1}$ & 11 & & & Modan & Fuentes et al.,2008;Fujii et al., 2000 \\
\hline Pise1 & 11 & $5740642-16730739$ & & Sensho & Izawall\&Iwasakizl, 2000 \\
\hline Pikur2 & 11 & 2840211-18372685 & & Kuroka & Goto, 1988 \\
\hline Pi38 & 11 & 19137900-21979485 & RM206, RM21 & CO39 and Tadukan & Gowda et al.,2006 \\
\hline Pik & 11 & 27314916-27532928 & $\begin{array}{l}\mathrm{k} 6816, \mathrm{k} 2167, \mathrm{k} 6438, \mathrm{k} 6415, \\
\mathrm{k} 8823, \mathrm{k} 8824, \mathrm{k} 3951, \mathrm{k} 39512\end{array}$ & K60 & $\begin{array}{l}\text { Hayasaka et al.,1995; Hayashi et } \\
\text { al.,2006 }\end{array}$ \\
\hline Pif & 11 & $24695583-28462103$ & & Chugoku 31-1 (St. No. 1) & Gowda et al.,2006 \\
\hline Pi34 & 11 & 19423000-19490000 & C1172, E2021 & Chubu 32 & Zenbayashi et al., 2002 \\
\hline Pia & 11 & 4073024-8078510 & yca72 & Aichi Asahi (J) & $\begin{array}{l}\text { Chauhan et al.,2002; Zenbayashi- } \\
\text { Sawata } \text { et al.,2005 }\end{array}$ \\
\hline Mpiz & 11 & $4073024-16730739$ & & Zenith $(\mathrm{J})$ & Goto, 1996 \\
\hline Piisi & 11 & 2840211-19029573 & & ImochiShirazu (J) & Goto, 1970 \\
\hline $\operatorname{PiCO39}(t)$ & 11 & $6304007-6888870$ & RGA8, RZ141, RGACO39 & $\mathrm{CO} 39$ & Chauhan et al., 2002; Kwon et al.,2008 \\
\hline Pilm2 & 11 & $13635033-28377565$ & $\begin{array}{l}\text { L457b, G2132b, RZ536x, } \\
\text { RG1109 }\end{array}$ & Teqing & Tabien et al.,2002; Zhou et al.,2004 \\
\hline Pi30(t) & 11 & $441392-6578785$ & OpZ11-f, RGA-IR14 & IR64 & Sallaud et al.,2003; Nguyen et al.,2006 \\
\hline $\operatorname{Pi7}(\mathbf{t})$ & 11 & $17850000-21075000$ & & RIL29 (Moroberekan) & Miyamoto et al.,2001 \\
\hline Pi44(t) & 11 & $22850000-29475000$ & & RIL29 (Moroberekan) & Chauhan et al.,2002 \\
\hline Pi49 & 11 & & $\mathrm{~K} 10$ and $\mathrm{K} 134$ & $\mathrm{CO} 39$ & Chen et al., 1999 \\
\hline Pik-m & 11 & 27314916-27532928 & $\begin{array}{l}\mathrm{k} 6816, \mathrm{k} 2167, \mathrm{k} 641, \mathrm{k} 6441, \\
\mathrm{k} 4731, \mathrm{k} 7237\end{array}$ & Tsuyuake & Sun et al.,2013; Wang et al.,2007 \\
\hline Pi18(t) & 11 & $26796917-28376959$ & RZ536 & Sweon 365 & Li et al.,2007 \\
\hline Pik-p & 11 & $27314916-27532928$ & k641, k39575, k403, k3957 & HR22 & Hayashi et al.,2006 \\
\hline Pik-s & 11 & 27314916-27532929 & $\begin{array}{l}\text { RM144, RM224, RM1233, } \\
\text { RM144,RM224, RM1233 }\end{array}$ & Shin 2 & Fjellstrom et al.,2004 \\
\hline Pi47 & 11 & & RM206 and RM224 & Cross between XZ3150 and the highly & Ahn et al.,2000 \\
\hline
\end{tabular}




\begin{tabular}{|c|c|c|c|c|c|}
\hline & & & & susceptible cultivar CO39 & \\
\hline $\mathrm{Pik}^{\mathrm{g}}$ & 11 & 27314916-27532930 & & GA20 & Tabien et al.,2000 \\
\hline $\mathbf{P i 6 0}(\mathrm{t})$ & 11 & & K1-4 and E12 & $93-11$ & Huang et al.,2011 \\
\hline Pi-1(t) & 11 & & RM224 & Samba mahsuri & Lei et al.,2013 \\
\hline Pi1 & 11 & & CRG11-7 and K28 & cv. C101LAC & Prasad et al.,2009 \\
\hline PBR & 11 & $20125000-30075000$ & & St. No. 1 & Fujii et al., 1995 \\
\hline Pi24(t) & 12 & $5242654-5556378$ & RGA 3 & Zhong 156/Azuenca (J) & $\begin{array}{l}\text { Zhuang et al.,2002 } \\
\text { Hua et al.,2012) }\end{array}$ \\
\hline $\mathrm{Pi}-42(\mathrm{t})$ & 12 & & $\begin{array}{l}\text { STS5, RRS44, RRS51, RRS60, } \\
\text { RRS63, } \\
\text { RRS6 and CRG 6-1 }\end{array}$ & DHR9 & Zhuang et al.,2002 \\
\hline Pi51(t) & 12 & & RM5364, RM27990 & Tianjingyeshengdao & Qu et al.,2006 \\
\hline Pi62(t) & 12 & $2426648-18050026$ & RG869 & Yashiromochi & Wu et al.,1996; Kumar et al.,2010 \\
\hline Pi6(t) & 12 & $1-6725831$ & RG869 & Apura & Wu et al., 1996 \\
\hline $\operatorname{Pi12(t)}$ & 12 & $6988220-15120464$ & & Hong-jiaozhan/Moroberekan (J) & Inukai et al., 1995 \\
\hline Pi4(t) & 12 & & RG869, RZ397 & Apura & Wu et al., 1996 \\
\hline $\operatorname{Pi31}(t)$ & 12 & 7731471-11915469 & O10-800 & IR64 & Sallaud et al., 2003; Nguyen et al.,2006 \\
\hline $\operatorname{Pi32}(\mathrm{t})$ & 12 & $13103039-18867450$ & AF6 & IR64 & Sallaud et al., 2003; Nguyen et al.,2006 \\
\hline Ipi(t) & 12 & & RG241X & BS125xWL02 & Causse et al.,1994 \\
\hline IPi3(t) & 12 & & RG241X & BS125xWL02 & Causse et al.,1994 \\
\hline Pita-2 & 12 & 10078620-13211331 & ta3 & Pi No.4 & Hayashi et al.,2006 \\
\hline Pi19(t) & 12 & $8826555-13417088$ & & Aichi Asahi & Inukai\& Nelson, 1994; Iwata et al., 1996 \\
\hline $\operatorname{Pi21}(t)$ & 12 & 5242654-5556378 & & Suweon 365 & Terashima et al.,2008 \\
\hline Pita & 12 & $10603772-10609330$ & SP4B9 and SP9F3 & $\begin{array}{l}\text { Yashiro-mochi and } \\
\text { Tsuyuake/Tadukan (I) }\end{array}$ & Hayashi et al., 2006 \\
\hline Pi58(t) & 12 & & RM27954, RM27933, RM3103 & HaoruxUS-2 & Zhou et al.,2006 \\
\hline $\operatorname{Pi39}(t)$ & 12 & & 39M6, 39M7 & Q15/Chubu 111 (J) & Bryan et al.,2000; Liu et al.,2007 \\
\hline Pi-GD-3(t) & 12 & 13950000 & RM179 & $\begin{array}{l}\text { Sanhuangzhan } 2 \text { x Lijiangxin-tuan- } \\
\text { heigu }\end{array}$ & Liu et al., 2005; He et al.,2012 \\
\hline Pi20(t) & 12 & $12875000-12950000$ & RM1337, RM5364, RM7102 & Asominori and IR24 & Liu et al.,2007; Liu et al., 2008 \\
\hline Pi-tq6 & 12 & $5758663-7731471$ & $\begin{array}{l}\text { RG341a, RG869, L102, } \\
\text { G1468a, RZ397, RZ257 }\end{array}$ & Teqing & Tabien et al., 2002; Zhou et al.,2004 \\
\hline Pi48 & 12 & & RM5364 and RM7102 & $\begin{array}{l}\text { Cross between XZ3150 and the highly } \\
\text { susceptible cultivar CO39 }\end{array}$ & Ahn et al.,2000 \\
\hline Pi61(t) & 12 & & M2 and S29 & $93-11$ & Huang et al.,2011 \\
\hline Pi157 & 12 & $12375000-15550000$ & & Moroberekan & Causse et al.,1994 \\
\hline
\end{tabular}


Table.2 List of cloned blast resistance genes with necessary information

\begin{tabular}{|c|c|c|c|c|c|c|}
\hline $\begin{array}{l}\text { Gene } \\
\text { Symbol }\end{array}$ & Chromosome & $\begin{array}{c}\text { Domain } \\
\text { combination }\end{array}$ & Cultivar name & $\begin{array}{l}\text { Cloning } \\
\text { Strategy }\end{array}$ & References & $\begin{array}{l}\text { Percentage } \\
(\%) \text { of total } \\
\text { cloned genes }\end{array}$ \\
\hline Pb1 & 11 & $\begin{array}{l}\text { CC-NBS- } \\
\text { LRR }\end{array}$ & Modan & Map Based & $\begin{array}{l}\text { Hayashi et al., } \\
2010\end{array}$ & \multirow{8}{*}{$36 \%$} \\
\hline $\begin{array}{l}\text { Pik- } \\
\text { h(Pi54) }\end{array}$ & 11 & NBS-LRR & Tetep & Map Based & $\begin{array}{l}\text { Sharma et al., } \\
2005\end{array}$ & \\
\hline Pikm & 11 & $\begin{array}{l}\text { CC-NBS- } \\
\text { LRR }\end{array}$ & Tsuyuake & Map Based & $\begin{array}{l}\text { Ashikawa et al., } \\
2008\end{array}$ & \\
\hline Pi-k & 11 & $\begin{array}{l}\text { CC-NBS- } \\
\text { LRR }\end{array}$ & Koshiminori & Map Based & $\begin{array}{l}\text { Wang et al., } \\
2013\end{array}$ & \\
\hline Pik-p & 11 & $\begin{array}{l}\text { CC-NBS- } \\
\text { LRR }\end{array}$ & HR22 & $\begin{array}{l}\text { Map Based in } \\
\text { silico }\end{array}$ & Yuan et al.,2011 & \\
\hline Pia & 11 & $\begin{array}{l}\text { CC-NBS- } \\
\text { LRR }\end{array}$ & Aichi Asahi & $\begin{array}{l}\text { Multifaceted } \\
\text { genomics } \\
\text { approach }\end{array}$ & $\begin{array}{l}\text { Okuyama et al., } \\
2011\end{array}$ & \\
\hline NLS1 & 11 & NBS-LRR & $\begin{array}{l}\text { nls1-1D/NLS1 } \\
\text { and Zhongsi } 2\end{array}$ & Map Based & $\begin{array}{l}\text { Ashkani et al., } \\
2014\end{array}$ & \\
\hline Pi54rh & 11 & $\begin{array}{l}\text { CC-NBS- } \\
\text { LRR }\end{array}$ & Oryzarhizomatis & $\begin{array}{l}\text { Allele mining } \\
\text { approach }\end{array}$ & Das et al., 2012 & \\
\hline Pi2 & 6 & NBS-LRR & Zhenshan 97 & Map Based & Liu et al., 2002 & \multirow{6}{*}{$27 \%$} \\
\hline Pi9 & 6 & NBS-LRR & $\begin{array}{l}75-1- \\
127(101141)\end{array}$ & Map Based & Qu et al., 2006 & \\
\hline Piz-t & 6 & $\begin{array}{l}\text { CC-NBS- } \\
\text { LRR }\end{array}$ & Toride 1 & Map Based & $\begin{array}{l}\text { Ashkani et al., } \\
2014\end{array}$ & \\
\hline Pid-2 & 6 & $\begin{array}{l}\text { Lectin } \\
\text { receptor }\end{array}$ & Digu & Map Based & Chen et al., 2006 & \\
\hline Pid3 & 6 & $\begin{array}{l}\text { CC-NBS- } \\
\text { LRR }\end{array}$ & Digu & $\begin{array}{l}\text { Silico homology } \\
\text { based }\end{array}$ & $\begin{array}{l}\text { Shang et al., } \\
2009\end{array}$ & \\
\hline $\mathbf{P i 2 5}$ & 6 & $\begin{array}{l}\text { CC-NBS- } \\
\text { LRR }\end{array}$ & Nipponbare & $\begin{array}{l}\text { In silico } \\
\text { approach }\end{array}$ & $\begin{array}{l}\text { Ashkani et al., } \\
2014\end{array}$ & \\
\hline Pi37 & 1 & NBS-LRR & St. No.1 & $\begin{array}{l}\text { Map Based in } \\
\text { silico }\end{array}$ & Chen et al., 2005 & \multirow{3}{*}{$14 \%$} \\
\hline Pit & 1 & $\begin{array}{l}\text { CC-NBS- } \\
\text { LRR }\end{array}$ & K59 & Map Based & $\begin{array}{l}\text { Hayashi \& } \\
\text { Yoshida, } 2009\end{array}$ & \\
\hline Pis-h & 1 & $\begin{array}{l}\text { CC-NBS- } \\
\text { LRR }\end{array}$ & Nipponbare & $\begin{array}{l}\text { Mutant } \\
\text { Screening }\end{array}$ & $\begin{array}{l}\text { Ashkani et al., } \\
2014\end{array}$ & \\
\hline Pib & 2 & NBS-LRR & Tohoku IL9 & Map Based & Wang et al., 1999 & $4.5 \%$ \\
\hline$\overline{P i 21}$ & 4 & NBS-LRR & AA-pi21 & $\begin{array}{l}\text { Map Based } \\
\text { Cloing }\end{array}$ & $\begin{array}{l}\text { Fukuoka et al., } \\
2009\end{array}$ & $4.5 \%$ \\
\hline Pi36 & 8 & $\begin{array}{l}\text { CC-NBS- } \\
\text { LRR }\end{array}$ & Q61 & $\begin{array}{l}\text { In silico map } \\
\text { based }\end{array}$ & Liu et al.,2005 & $4.5 \%$ \\
\hline Pi5 & 9 & $\begin{array}{l}\text { CC-NBS- } \\
\text { LRR }\end{array}$ & RIL260 & $\begin{array}{l}\text { Map Based } \\
\text { Cloing }\end{array}$ & Lee et al., 2009 & $4.5 \%$ \\
\hline Pi-ta & 12 & NBS-LRR & Tadukan & $\begin{array}{l}\text { Map Based } \\
\text { Cloing }\end{array}$ & $\begin{array}{l}\text { Bryan et al., } \\
2000\end{array}$ & $4.5 \%$ \\
\hline
\end{tabular}


Table.3 Examples of MAS and gene pyramiding for blast resistance in rice

\begin{tabular}{|c|c|c|c|c|}
\hline Target Traits & Gene(s)/QTL (s) & $\begin{array}{l}\text { Type/name of } \\
\text { marker(s) used }\end{array}$ & $\begin{array}{l}\text { Target } \\
\text { variety/application }\end{array}$ & References \\
\hline Blast resistance & Pi1,Piz-5,Pita & RFLP, SSR,ISSR & $\mathrm{CO} 39$ & Hittalmani et al., 2000 \\
\hline Blast resistance & Pi1,Piz-5,Pi2,Pita & RFLP, SSR,ISSR & $\mathrm{CO} 39$ & Hittalmani et al., 2000 \\
\hline $\begin{array}{l}\text { Bacterial blight (BB) } \\
\text { resistance and Blast } \\
\text { resistance }\end{array}$ & Xa21 \& Piz & $\begin{array}{l}\text { STS and transgene } \\
\text { specific marker }\end{array}$ & IR50 & Narayanan et al., 2004 \\
\hline Blast resistance & Pi1 & Microsatellite, SSR & Zhenshan97 & Liu et al., 2003 \\
\hline Blast resistance & Pi1,Pi2 & Microsatellite, SSR & Zhenshan97 & He et al., 2004 \\
\hline Blast resistance & $\begin{array}{l}\text { Pid1, Pib and } \\
\text { Pita2 }\end{array}$ & SSR & G46B & Chen et al., 2004 \\
\hline Blast resistance & $\mathrm{Pi} 2$ & SSR & Zhenshan97B & Chen et al., 2004 \\
\hline Blast resistance & $\mathrm{Pi}-\mathrm{z}$ & Microsatellite & $\begin{array}{l}\text { Used in parental material } \\
\text { for gene surveys }\end{array}$ & Fjellstrom et al., 2006 \\
\hline $\begin{array}{l}\text { Submergence tolerance, } \\
\text { BPH resistance, } \\
\text { Bacterial blight } \\
\text { resistance, Blast } \\
\text { resistance and quality }\end{array}$ & $\begin{array}{l}\text { Subchr9 } \\
\text { QTL,Xa21,Bph } \\
\text { and blast QTLs } \\
\text { and quality loci }\end{array}$ & SSR and STS & KDML105 & Toojinda et al., 2005 \\
\hline Blast resistance & Pi-ta & Gene specific marker & $\begin{array}{l}\text { Advanced breeding lines } \\
\text { for rice breeding } \\
\text { programmes. }\end{array}$ & Wang et al., 2007 \\
\hline Blast resistance & $\mathrm{Pi} 1, \mathrm{Pi} 2$ and $\mathrm{Pi} 33$ & SSR & Jin23B & Chen et al.,2008 \\
\hline Blast resistance & Two QTLs & $\begin{array}{l}\text { Microsatellite } \\
\text { markers }\end{array}$ & RD6 & $\begin{array}{l}\text { Wongsaprom et al., } \\
2010\end{array}$ \\
\hline Blast resistance & Pish\&Pib & SSR & CO39 & Koide et al., 2010 \\
\hline Blast resistance & $\begin{array}{l}\text { Four resistant } \\
\text { QTLs }\end{array}$ & SSR & $\mathrm{F}_{4}$ generation lines & $\begin{array}{l}\text { Sreewongchai et al., } \\
2010\end{array}$ \\
\hline Blast resistance & $\mathrm{Pi}-9(\mathrm{t})$ & Marker pB8 & Hybrid restorer Luhui17 & Wen et al., 2012 \\
\hline Blast resistance and BB & $\begin{array}{l}\mathrm{Pi} 1 \text { and } \mathrm{Pi} 2 \text { for } \\
\text { blast resistance } \\
\text { and Xa23 for BB }\end{array}$ & SSR & Rongfeng B & Fu et al., 2012 \\
\hline Blast resistance & Piz-5 and Pi54 & SSR & Pusa 1602 and Pusa 1603 & Singh et al., 2012 \\
\hline Blast resistance & Putative Piz & SSR & MR219 & Miah et al., 2015 \\
\hline Blast resistance & $\begin{array}{l}\text { Pi21, Pi34, } \\
\text { QBR4-2 and } \\
\text { QBR12-1 }\end{array}$ & SSR & NILs for evaluation & Fukuoka et al., 2015 \\
\hline Blast resistance & Pi 9,Pita & $\begin{array}{l}\text { Gene linked and } \\
\text { microsatellite marker }\end{array}$ & Pusa Basmati 1 & Khanna et al., 2015 \\
\hline $\begin{array}{l}\text { Bacterial blight and } \\
\text { Blast resistance }\end{array}$ & Xa21 \& Pi 54 & $\begin{array}{l}\text { STS marker pTA248 } \\
\text { and functional } \\
\text { marker Pi54 MAS }\end{array}$ & DRR17B & $\begin{array}{l}\text { Balachiranjeevi et al., } \\
2015\end{array}$ \\
\hline $\begin{array}{l}\text { Bacterial blight, Blast, } \\
\text { and Brown plant } \\
\text { hopper resistance }\end{array}$ & $\begin{array}{l}\text { Xa4, xa5, Xa21, } \\
\text { Pi40 and Bph18 }\end{array}$ & SSR & Japonica rice cultivar & Suh et al., 2015 \\
\hline $\begin{array}{l}\text { Blast and Bacterial } \\
\text { blight resistance }\end{array}$ & Pi2 \& Xa23 & SSR and indel marker & GZ63-4S & Jiang et al., 2015 \\
\hline Blast resistance & Pita and Pi54 & SSR & $\begin{array}{l}\text { Used in rice breeding } \\
\text { programme }\end{array}$ & Mahesh et al., 2016 \\
\hline Blast resistance & Pi9,Pizt andPi54 & Gene linked markers & OSGY31 & Xiao et al., 2017 \\
\hline
\end{tabular}




\section{MAS and Gene Pyramiding for blast} resistance

Marker- assisted selection is an efficient way to select the desirable characters indirectly. The selection and identification of markers linked to the gene of interest is the basic prerequisite for marker assisted selection. In case of blast resistance, application of marker assisted selection is very powerful as single or a few genes are involved in the resistance mechanism. Development of durable blast resistant rice varieties against $M$. oryzae progressed with the availability of different molecular markers used for marker assisted selection (Ashkani et al., 2012).

With the advent of molecular biology, marker assisted selection (MAS) facilitate gene pyramiding in plants. Gene pyramiding is one of the most effective strategies for achieving durable and multiple resistances. This approach uses both traditional and modern molecular biology approaches depending on the available resources to introgress more than one gene for a specific trait into a single genetic background. Availability of various molecular markers helps in the rapid detection and introgression of resistant genes into susceptible rice varieties as compared to conventional phenotypic screening.

The selection of blast resistance genes through marker assisted selection is very precise because of the true interaction of the particular resistance (R) gene with the avirulence gene.

Gene pyramiding has been successfully applied to combine several genes of blast resistance in rice. Three important blast resistance genes Pi1, Piz-5 and Pita with closely linked RFLP and PCR based markers have been introgressed into a susceptible cultivar CO39 through MAS. Compared to the plant with Piz-5 alone, two and three gene combinations including Piz-5 showed enhanced resistance to blast (Hittalmani et al., 2000). After few years later on the same cultivar CO39, Pish\&Pib genes were also introgressed with MAS (Koide et al., 2010). Three genes, Pi-d(t)1,Pi-b, and Pi-ta2, have been fixed into a donor line of rice, G46B (Chen et al., 2004), and two genes, Pi1 and $\mathrm{Pi} 2$, have been fixed into cv. Zhenshan 97 (He, 2004).

Pusa1602 and Pusa1603 lines have been developed by incorporating the blast resistance genes Piz-5 and Pi54 through MAB (Singh et al., 2012). The leaf and neck blast resistance have been developed through introgression of the Pi1 and Pi2 genes, respectively, using $\mathrm{MAB}$ programmes $(\mathrm{Fu}$ et al., 2012). Two quantitative trait loci (QTLs) that confer resistance to blast disease have been successfully introgressed into RD6 using MAS (Wongsaprom et al., 2010).In that same year again four QTLs for blast resistance were introgressed into $\mathrm{F}_{4}$ lines using marker assisted selection (Sreewongchai et al.,2010).

Pyramiding of resistance genes with different pathogens and insect is of great significance for plant breeding. Narayanan et al., (2004) pyramided two major R-genes Xa21 and Piz for bacterial blight and blast resistance into rice using MAS and genetic transformation. For bacterial blight, blast, and Brown plant hopper resistance gene Xa4, xa5, Xa21, Pi40 and $\mathrm{Bph} 18$ has been introgressed into japonica rice cultivar (Suh et al., 2015). Recently a study was doneon three major blast resistance genes Pi9, Pizt andPi54 to find out the best combination for pyramiding and result showed that combination of Pizt and Pi54 gives higher resistant level and better additive effects on panicle blast resistant than $\mathrm{Pi} 9$ and $\mathrm{Pi} 54$ combination (Xiao et al., 2017).Some examples of MAS for gene pyramiding in rice are shown in Table 3. 
The use of resistant cultivar is a powerful tool to develop sustainable and environmental favourable rice production systems. Rice blast is a serious concern in the present days breeding program, as many pathogen strain overcome resistance within a short period of time because of evolution of pathogen strains. Therefore, further research is still required to exploit tools, knowledge in breeding programs. Although, more than 100 blast resistance genes were identified in different rice genotypes and 22 of them were cloned and characterized at the molecular level, they provide resistance to specific pathotypes. So we need to identify more durable and suitable blast resistance genes that confer broadspectrum resistance to different pathotypes of $M$. oryzae. Recent advances in rice genomics and molecular biology studies comes out with new techniques like fine mapping, cloning of blast resistance gene and also gene pyramiding with MAS which ultimately helps in the deployment of various resistant genes in rice background. This review will be helpful to study the necessary information for identification of more than 100 blast resistance genes and also a large number of QTLs (more than 350). We have also discussed mapping and cloning of blast resistance genes and also gene pyramiding with marker assisted selection for different biotic stress mainly rice blast. As blast resistance genes are mostly independent, information from this review can be utilized by plant breeders to develop new cultivar of improved agronomic background with more number of resistant genes for marker assisted breeding programmes. Reported DNA markers can also be used in future rice breeding program to detect the genes and QTLs of interest.

\section{Acknowledgement}

We are greatful to Dean, College of Post Graduate Studies and Chairman, School of
Crop Improvement, CAU (Imphal) for support. Ashim Debnath is thankful to his advisor and also UGC, Govt. of India for National Fellowship for Students of OBC.

\section{References}

Ahn, S., Kim, Y., Han, S., et al., 1996. Molecular mapping of a gene for resistance to a Korean isolate of rice blast. Rice Genet. Newsl., 13: 74-76.

Ahn, S.N., Hong, Y.K.H.C., Han, S.S., Choi, H.C., McCouch, S.R., and Moon, H.P. 1997. Mapping of genes conferring resistance to Korean isolates of rice blast fungus using DNA markers. Kor. J. Breed., 29(4): 416-423.

Ahn, S.N., Kim, Y.K., Hong, H.C., et al., 2000. Molecular mapping of a new gene for resistance to rice blast (Pyricularia grisea Sacc.). Euphytica., 116: 17-22.

Ashikawa, I., Hayashi, N., Yamane, H., et al., 2008. Two adjacent nucleotide-binding site-leucine-rich repeat class genes are required to confer Pikm-specific rice blast resistance. Genetics, 180: 2267-2276.

Ashkani, S., Rafii, M.Y., Rusli, I., Sariah, M., Abdullah, S.N.A., Harun, A.R., Latif, M.A. 2012. SSRs for marker-assisted selection for blast resistance in rice (Oryza sativa L.). Plant Mol Biol Rep., 30:79-86.

Ashkani, S., Rafii, M.Y., Shabanimofrad, M., Ghasemzadeh, A., Ravanfar, S. A., and Latif, M.A. 2014. Molecular progress on the mapping and cloning of functional genes for blast disease in rice (Oryza sativa L.): current status and future considerations. Crit. Rev. Biotechnol., 115.

Balachiranjeevi, C.H., Bhaskar, N.S., Abhilash, V., Akanksha, S., Viraktamath., B.C., Madhav, M. S., Hariprasad, A.S., Laha, G.S., Prasad, M.S., Balachandran, S.M., et al., 2015. Mol Breeding, 35:151.

Ballini, E., Morel, J.B., Droc,G., et al., 2008. A genome-wide meta analysis of rice blast resistance genes and quantitative trait loci 
provides new insights into partial and complete resistance. Mol. Plant Microbe. Interact., 21: 859-868.

Barman, S., Gowda, M., Venu, R., and Chattoo, B. 2004. Identification of a major blast resistance gene in the rice cultivar “Tetep'. Plant Breeding, 123: 300-302.

Berruyer, R., Adreit, H., Milazzo, J., Gaillard, S., Berger, A., and Dioh, W.D. 2003.Identification and fine mapping of $\mathrm{Pi33}$, the rice resistance gene corresponding to the Magnaporthe grisea avirulence gene ACE1. Theor. Appl. Genet., 107(6): 1139-1147.

Bryan, G.T., Wu, K.S., Farrall, L. et al., 2000. A single amino acid difference distinguishes resistant and susceptible alleles of the rice blast resistance gene $\mathrm{Pi}$ ta. The Plant Cell Online, 12: 2033-2045.

Causse, M.A., Fulton, M., Cho, Y.G., Ahn, S.N., Chunwongse, J., Wu, K., and Harrington, S.E. 1994. Saturated molecular map of the rice genome based on an interspecific backcross population. Genetics, 138(4): 1251.

Chauhan, R., Farman, M., Zhang, H.B., and Leong, S. 2002. Genetic and physical mapping of a rice blast resistance locus, PiCO39 (t) that corresponds to the avirulence gene AVR1-CO39 of Magnaporthe grisea. Mol. Genet. Genom., 267(5): 603-612.

Chen, D.H., Dela, V.M., Inukai, T., et al., 1999. Molecular mapping of the blast resistance gene, Pi44 (t), in a line derived from a durably resistant rice cultivar. Theoret. Appl. Genet., 98: 1046-1053.

Chen, H.Q., Chen, Z.X., Ni, S., Zuo, S.M., Pan, X.B., and Zhu, X.D. 2008. Pyramiding three genes with resistance to blast by marker assisted selection to improve rice blast resistance of Jin 23B, application, Zhongguo Shuidao Kexue. Chin. J. Rice Sci., 22(1): 23-27.

Chen, J., Shi, Y., Liu, W. et al., 2011. A "Pid3" allele from rice cultivar Gumei2 confers resistance to "Magnaporthe oryzae”. J. Genet. Genom., 38: 209-216.
Chen, S., Wang, L., Que, Z., Pan, R., and Pan, Q. 2005. Genetic and physical mapping of $\mathrm{Pi} 37(\mathrm{t})$, a new gene conferring resistance to rice blast in the famous cultivar St. No. 1. Theor. Appl. Genet., 111(8): 15631570.

Chen, X., Li, S., Xu, J., Zhai, W., Ma, Z.B., and $\mathrm{Ma}$, Y. 2004. Identification of two blast resistance genes in a rice variety, Digu. $J$. Phytopathol., 152(2): 77-85.

Chen, X., Shang, J., Chen, D., Lei, C., Zou, Y., Zhai, W., and Cao, G. 2006. AB-lectin receptor kinase gene conferring rice blast resistance. Plant J., 46(5): 794-804.

Couch, B.C., and Kohn, L.M. 2002. A multilocus gene genealogy concordant with host preference indicates segregation of a new species, Magnaporthe oryzae, from M. grisea. Mycologia., 94: 683-693.

Das, A., Soubam, D., Singh, P. et al., 2012. A novel blast resistance gene, Pi54rh cloned from wild species of rice, Oryza rhizomatis confers broad spectrum resistance to Magnaporthe oryzae., Funct. Integr. Genomics., 12: 215-228.

Dean, R., Van kan, J.A.L., Pretorius, Z.A., Kim, E., Kosack, H., Pietro, A.D., Spanu, P.D., Rudd, j.j., Dickman, M., Kahmann, R. et $a l .$, 2012. The Top 10 fungal pathogens in molecular plant pathology. Molecular plant pathology., 13(4): 414-430.

Deng, Y., Zhu, X., Shen, Y., and He, Z. 2006. Genetic characterization and fine mapping of the blast resistance locus Pigm (t) tightly linked to $\mathrm{Pi} 2$ and $\mathrm{Pi} 9$ in a broad-spectrum resistant Chinese variety. Theor. Appl. Genet. 113(4): 705-713.

Dwinita, W.U., Sugiono, M., Hajrial, A., Asep, S., Ida, H. 2008. Blast resistance genes in wild rice Oryza rufipogon and rice cultivar IR64. Ind J Agric., 1:71-76.

Fjellstrom, R., Conaway-Bormans, C.A., McClung, A.M. et al., 2004. Development of dna markers suitable for marker assisted selection of three genes conferring Resistance to multiple pathotypes. Crop Sci., 44: 1790-1798.

Fjellstrom, R., McClung, A.M., and Shank, A.R. 2006. SSR markers closely linked to 
the Pi-z locus are useful for selection of blast resistance in a broad array of rice germplasm. Molecular Breeding, 17: 149-57.

Fu, C., Wu, T., Liu, W. et al., 2012. Genetic improvement of resistance to blast and bacterial blight of the elite maintainer line Rongfeng B in hybrid rice (Oryza sativa L.) by using marker-assisted selection. Afr. J. Biotechnol., 11: 13104-13114.

Fuentes, J.L., Correa-Victoria, F.J., Escobar, F. et al., 2008. Identification of microsatellite markers linked to the blast resistance gene $\mathrm{Pi}-1$ (t) in rice. Euphytica., 160: 295-304.

Fujii, H.Y., Saito, K., Sugiura, N., Hayashi, N., Tsuji, T., and Izawa, T.I.M. 2000. Identification of a RFLP marker tightly linked to the panicle blast resistance gene, $\mathrm{Pb} 1$, in rice. Breed. Sci., 50 (3): 183-188.

Fujii, K., Hayano-Saito, Y., Shumiya, A., and Inoue, M. 1995. Genetical mapping based on the RFLP analysis for the panicle blast resistance derived from a rice parental line St. No. 1. Breed Sci., 45: (Suppl. 1) 209.

Fukuoka, S., and Okuno, K. 2001. QTL analysis and mapping of pi21, a recessive gene for field resistance to rice blast in Japanese upland rice. Theor. Appl. Genet., 103: 185-190.

Fukuoka, S., Okuno, K., and Kawase, M. 2007. Rice blast disease gene Pi21, resistance gene pi21 and utilization thereof. Patent WO/2007/000880.

Fukuoka, S., Saka, N., Koga, H. et al., 2009. Loss of function of a proline containing protein confers durable disease resistance in rice. Science., 325: 998-1001.

Fukuoka, S., Saka, N., Mizukami, Y., Koga, H., Yamanouchi, U., Yoshioka, Y., Hayashi, N., Ebana, K.., Mizobuchi, R., and Yano, M. 2015. Gene pyramiding enhances durable blast disease resistance in rice. Scientific Reports, 5: 73-77.

Fukuoka, S., Yamamoto, S.I., Mizobuchi, R., Yamanouchi, U., Ono, K., Kitazawa, N., and Koizumi, S. (2014). Multiple functional polymorphisms in a single disease resistance gene in rice enhance durable resistance to blast, Sci. Rep., 4: 4550, http://dx.doi.org/10.1038/srep 04550 .

Fukuta, Y., Yanoria, M., Mercado-Escueta, D., et al., 2004. Quantitative trait loci (QTL) reactions to rice blast isolates from Japan and the Philippines. In: Kawasaki S, ed. Rice blast: interaction with rice and control. Springer., 113-21.

Goto, I. 1976. Genetic studies on resistance of rice plant to blast fungus, difference in resistance to the blast disease between Fukunishiki and its parental cultivar, Zenith. Ann. Phytopathol. Soc. Jpn. 42(3): 253-260.

Goto, I. 1988. Genetic studies on resistance of rice plant to blast fungus, 7: blast resistance genes of Kuroka. Ann. Phytopathol. Soc. Jpn., 54: 460-465.

Goto,I. 1970. Genetic studies on the resistance of rice plant to the blast fungus $\mathrm{I}$. Inheritance of resistance in crosses Sensho x H-79 and Imochishirazu x H-79. Ann. Phytopathol. Soc. Jpn., 36: 304-312.

Gowda, M., Roy-Barman, S., and Chattoo, B. 2006. Molecular mapping of a novel blast resistance gene $\mathrm{Pi} 38$ in rice using SSLP and AFLP markers. Plant Breed., 125: 596-599.

Gu, K., Yang, B., Tian, D., Wu, L., Wang, D., Sreekala, C., Yang, F., Chu, Z., Wang, G., White, F.F., Yin, Z. 2005. R gene expression induced by a type-II effector triggers disease resistance in rice. Nature 435:1122-1125. doi:10.1038/ nature 03630 .

Hayasaka, H. 1996. RFLP mapping of a rice blast resistance gene Pi-k. Breed. Sci., 46 (Suppl. 2) 68 (in Japanese).

Hayasaka, H., Takamatsu, M., Kuboki, Y., et $a l .$, 1995. Mapping genes conferring rice blast resistance in rice variety Kasalath using RFLP markers. II. Linkage analysis of the resistance gene on chromosome 6 . Breeding Sci., 45: 168.

Hayashi, K., and Yoshida, H. 2009. Refunctionalization of the ancient rice blast disease resistance gene Pit by the 
recruitment of a retrotransposon as a promoter. Plant J., 57: 413-25.

Hayashi, K., Yoshida, H., and Ashikawa, I. 2006. Development of PCR-based allelespecific and InDel marker sets for nine rice blast resistance genes. Theor. Appl. Genet., 113 (2): 251-260.

Hayashi, N., Inoue, H., Kato, T. et al., 2010. Durable panicle blast resistance gene $\mathrm{Pb} 1$ encodes an atypical CC-NBS-LRR protein and was generated by acquiring a promoter through local genome duplication. Plant J., 64: 498-510.

Hayman, B.I. 1958. The separation of epistatic from additive and dominance variation in generation means. Heredity, 12: 371-390.

He, X., Liu, X., Wang, L., et al., 2012. Identification of the novel recessive gene pi55 (t) conferring resistance to Magnaporthe oryzae. Sci. China Life Sci., 55: 141-9.

He, Y. 2004. Gene pyramiding to improve hybrid rice by molecular marker techniques. Gene., 3: 4.

Hittalmani, S., Parco, A., Mew, T. et al., 2000. Fine mapping and DNA marker-assisted pyramiding of the three major genes for blast resistance in rice. Theoret. Appl. Genet., 100: 1121-1128.

Hua, L., Wu, J., Chen, C., et al., 2012. The isolation of Pi1, an allele at the Pik locus which confers broad spectrum resistance to rice blast. Theoret. Appl. Genet., 125: 1047-55.

Huang, H., Huang, L., Feng, G., et al., 2011. Molecular mapping of the new blast resistance genes $\mathrm{Pi} 47$ and $\mathrm{Pi} 48$ in the durably resistant local rice cultivar Xiangzi 3150. Phytopathology, 101: 620 626.

Inukai, T., and Nelson, R. 1994. Mapping for blast resistance gene H-3 derived from rice cuhivar Pai-Kan-Tao. Rep Hokkaido Br Crop Sol See Japan Jap Soc Breed., 35: 54-55.

Inukai, T., Nelson, R., Zeigler, R., Sarkarung, S., Mackill, D., Bonman, J., and Kinoshita,T. 1995. Genetic analysis of blast resistance in tropical rice cultivars using near isogenic lines, In: G.S. Khush (Ed.), Rice Genetics III. Proc 3rd Int Rice Genet Symp, Oct. 16-20 1995, Manila, The Philippines. pp. 447-450.

Ise, K. 1991. Linkage analysis of some blast resistance gene in rice, Oryza sativa L., Jpn. J. Breed., 42 (Suppl. 2): 388-389 (in Japanese).

Iwata, N. 1996. Registration of new gene symbols, Rice Genet. News 13:12-18.

Izawall, T., and Iwasakizl, M. 2000. Identification of a RFLP marker tightly linked to the panicle blast resistance gene, $\mathrm{Pb} 1$, in rice. Breeding Sci., 50: 183-188.

Jeon, J.S., Chen, D. Yi, G.H., et al., 2003. Genetic and physical mapping of Pi5 (t), a locus associated with broad-spectrum resistance to rice blast. Mol. Genet. Genomics., 269: 280-289.

Jeung, J.U., Kim, B.R., Cho, Y.C., Han, S.S., Moon, H.P., Lee, Y.T., and Jena, K.K. 2007. A novel gene, Pi40 (t), linked to the DNA markers derived from NBS-LRR motifs confers broad spectrum of blast resistance in rice. Theor. Appl. Genet., 115:1163-1177.

Jiang, J., Yang, D., Ali, J., and Mou, T. 2015. Molecular marker-assisted pyramiding of broad-spectrum disease resistance genes, $\mathrm{Pi} 2$ and Xa23, into GZ63-4S, an elite thermo-sensitive genic male-sterile line in rice. Mol. Breeding., 35:83.

Jiang, N., Li, Z., Wu, J., et al., 2012. Molecular mapping of the Pi2/9 allelic gene Pi2-2 conferring broad-spectrum resistance to Magnaporthe oryzae in the rice cultivar Jefferson. Rice, 5: 29.

Khan, M.A.I., Sen, P.P., Bhuiyan, R., Kabir, E., Chowdhury, A.K., Fukuta, Y., Ali, A., and Latif, M.A. 2014. Phenotypic screening and molecular analysis of blast resistance in fragrant rice for marker assisted selection. C.R. Biologies, 337:318-324.

Khanna, A., Sharma, V., Ellur, R.K., Shikari, A.B., Krishnan, S.G., Singh, U.D., Prakash, D., Sharma, T.R., Rathour, R., Variar, M., et al., 2015. Indian J. Genet., 75(4): 417-425. 
Khush, G.S. 2005. What it will take to feed 5.0 billion rice consumers in 2030, Plant Mol. Biol., 59: (1): 1-6.

Khush, G.S., and Jena, K. 2009. Current status and future prospects for research on blast resistance in rice (Oryza sativa L.), in: X. Wang, B. Valent (Eds.), Advances in Genetics, Genomics and Control of Rice Blast Disease. Springer., Dordrecht, pp. $1-10$.

Kinoshita, T., and Kiyosawa, S. 1997. Some considerations on linkage relationships between Pii and Piz in the blast resistance of rice. Rice. Genet. Newslett., 14: 57-9.

Kiyosawa, S. 1966. Studies on inheritance of resistance of rice varieties to blast: 3 . Inheritance of resistance of a rice variety Pi No. 1 to the blast fungus. Jpn J Breed., 16: 243-50.

Koide, Y., Kawasaki, A., Telebanco-Yanorial, M.J., Hairmansis, A., Nguyet, N.T.M., Bigirimana, J., Fujita, D., Kobayashi, N., and Fukuta, Y. 2010. Development of pyramided lines with two resistance genes, Pish and Pib, for blast disease (Magnaporthe oryzae $\mathrm{B}$. Couch) in rice (Oryza sativa L.). Plant Breeding, 129:670-675.

Koide, Y., Kobayashi, N., Xu, D., Fukuta, Y. 2009. Resistance genes and selection DNA markers for blast disease in rice (Oryza sativa L.). Jpn Agric Res Q., 43: 255-80.

Koide, Y., Telebanco-Yanoria, M.J., Fukuta, Y., and Kobayashi, N. 2013. Detection of novel blast resistance genes, Pi58 (t) and Pi59 (t), in a Myanmar rice landrace based on a standard differential system. Molecular Breeding, 32: 241-52.

Koizumi, S. 2007. Durability of resistance to rice blast disease, JIRCAS Working Rep. 53: $1-10$.

Kumar, P., Pathania, S., Katoch, P. et al., 2010. Genetic and physical mapping of blast resistance gene $\mathrm{Pi}-42(\mathrm{t})$ on the short arm of rice chromosome 12. Molecular Breeding, 25: 217-28.

Kwon, S.W., Cho, Y.C. Kim, Y.G. Suh, J.P., Jeung, J.U., Roh, J.H., and Lee, Y.T.
2008. Development of near isogenic japonica rice lines with enhanced resistance to Magnaporthe grisea. Mol. Cells., 25(3): 407-416.

Langridge, P., Lagudah, E.S., Holton, T. et al., 2001. Trends in genetic and genome analyses in wheat: a review. Crop Pasture Sci., 52: 1043-1077.

Lee, S.K., Song, M.Y., Seo, Y.S. et al., 2009. Rice Pi5-mediated resistance to Magnaporthe oryzae requires the presence of two coiled-coilnucleotidebinding-leucine-rich repeat genes. Genet., 181: 1627-38.

Lei, C., Hao, K., Yang, Y., et al., 2013. Identification and fine mapping of two blast resistance genes in rice cultivar 9311. Crop J., 1: 2-14.

Lei, C., Huang, D., Li, W., Wang, J., Liu, Z., Wang, X., and Ling, Z. 2005. Molecular mapping of a blast resistance gene in an indica rice cultivar Yanxian No. 1. Rice Genet. Newslett. 22:76-77.

Li, L.Y., Wang, L., Jing, J.X., Li, Z.Q., Lin, F., Huang, L.F., and Pan, Q.H. 2007. The Pik-m gene, conferring stable resistance to isolates of Magnaporthe oryzae, was finely mapped in a crossover-cold region on rice chromosome 11. Mol. Breed., 20(2): 179-188.

Lin, F., Chen, S., Que, Z., et al., 2007. The blast resistance gene Pi37 encodes a nucleotide binding site-leucine-rich repeat protein and is a member of a resistance gene cluster on rice chromosome 1. Genetics, 177: $1871-80$.

Linh, L.H., Hang, N.T., Jin, F. X., Kang, K.H., Lee, Y.T., Kwon, S.J., and Ahn, S.N. 2008. Introgression of a quantitative trait locus for spikelets per panicle from Oryza minuta to the $O$. sativa cultivar Hwaseongbyeo. Plant Breeding, 127(3): 262-267.

Liu, B., Zhang, S., Zhu, X., et al., 2004. Candidate defense genes as predictors of quantitative blast resistance in rice. Molecular Plant- Microbe Interact., 17: 1146-1152. 
Liu, S., Li, X., Wang, C. et al., 2003. Improvement of resistance to rice blast in Zhenshan 97 by molecular marker-aided selection. Acta. Bot. Sin., 45:1346-50.

Liu, W.G., Jin, S.J., Zhu, X.Y., Wang, F., Li, J.H., Liu, Z.R., and Liu, Y.B. 2008. Improving blast resistance of a thermosensitive genic male sterile rice line GD$8 \mathrm{~S}$ by molecular marker-assisted selection, Rice Sci., 15(3): 179- 185.

Liu, X., Lin, F., Wang, L., and Pan, Q. 2007. The in silico map-based cloning of Pi36, a rice coiled-coil-nucleotide-binding siteleucine-rich repeat gene that confers racespecific resistance to the blast fungus. Genetics, 176: 2541-2549.

Liu, X., Wang, L., Chen, S., Lin, F., and Pan, Q. 2005. Genetic and physical mapping of Pi36(t), a novel rice blast resistance gene located on rice chromosome 8. Mol. Genet. Genomics., 274(4): 394-401.

Liu, X., Yang, Q., Lin, F., Hua, L., Wang, C., Wang, L., and Pan, Q. 2007. Identification and fine mapping of Pi39(t), a major gene conferring the broad-spectrum resistance to Magnaporthe oryzae. Mol. Genet. Genomics., 278 (4): 403-410.

Liu, Y., Liu, B., Zhu, X., et al., 2012. Finemapping and molecular marker development for Pi56 (t), a NBS-LRR gene conferring broad spectrum resistance to Magnaporthe oryzae in rice. Theoret. Appl. Genet., 126: 985-998.

Liu, S.P., Li, X., Wang, C., Li, X.H., He, Y.Q. 2003. Improvement of resistance to rice blast in Zhenshan 97 by molecular marker aided selection. Acta Bot Sinica 45:13461350.

Ma, J., Lei, C., Xu, X., Hao, K., Wang, J., Cheng, Z., Ma, X., Ma, J., Zhou, K., Zhang, et al., 2015. Pi64, Encoding a Novel CC-NBS-LRR Protein, Confers Resistance to Leaf and Neck Blast in Rice. The American Phytopathological Society 28 (5): pp. 558-568.

Mahesh, H.B., Shirke, M.D., Singh, S., Rajamani, A., Hittalmani, S., Wang, G., and Gowda, M. 2016. Indica rice genome assembly, annotation and mining of blast disease resistance genes BMC Genomics., 17: 242.

McCouch, S.R., Teytelman, L., Xu, Y. et al., 2002. Development and mapping of 2240 new SSR markers for rice (Oryza sativa L.). DNA Res., 9: 199-207.

Melchinger, A.E., Utz, H.F., Schon, C.C. 1998. Quantitative trait locus (QTL) mapping using different testers and independent population samples in maize reveals low power of QTL detection and large bias in estimates of QTL effects. Genetics, 149(1): 383-403.

Miah, G., Rafii, M., Ismail, M., Puteh, A., Rahim, H., Asfaliza, R., and Latif, M. 2013. Blast resistance in rice: a review of conventional breeding to molecular approaches, Mol. Biol. Rep., 40(3): 23692388.

Miah, G., Rafii, M.Y., Ismail, M.R., Puteh, A.B., Rahim, H.A., and Latif, M.A. 2015. Recurrent parent genome recovery analysis in a marker-assisted backcrossing program of rice (Oryza sativa L.) C.R. Biologies., 338: 83-94.

Miyamoto, M., Yano, M., and Hirasawa, H. 2001. Mapping of quantitative trait loci conferring blast field resistance in the Japanese upland rice variety Kahei. Breed. Sci., 51: 257-261.

Mohamad, O., Nazir, B.M., Alias, I., Azlan, S., Abdul Rahim, H., Abdullah, M.Z., Othman, O., Hadzim, K., Saad, A., Habibuddin, H., and Golam, F. 2006. Development of improved rice varieties through the use of induced mutations in Malaysia. Plant Mutat. Rep., 1(1): 27-33.

Monosi, B., Wisser, R., Pennill, L., and Hulbert, S. 2004. Full-genome analysis of resistance gene homologues in rice. Theor. Appl. Genet., 109(7): 1434-1447.

Narayanan, N.N., Niranjan, B., Norman, P.O., Casiana, M.V., Samuel, S.G., Karabi, D. and Datta, S.K. 2004. Molecular breeding: marker assisted selection combined with biolistic transformation for blast and bacterial blight resistance in 
Indica rice (cv. CO39). Mol. Breeding, 14: 61-71.

Nguyen,T., Koizumi, S., La, T., Zenbayashi, K., Ashizawa, T., Yasuda, N., and Miyasaka, A. 2006. Pi35 (t), a new gene conferring partial resistance to leaf blast in the rice cultivar Hokkai188. Theor, Appl. Genet., 113(4): 697-704.

Okuyama, Y., Kanzaki, H., Abe, A. et al., 2011. A multifaceted genomics approach allows the isolation of the rice Pia-blast resistance gene consisting of two adjacent NBS-LRR protein genes. Plant J., 66: 467-479.

Pan, Q., Tanisaka, T., and Ikehashi, H. 1997. Studies on the genetics and breeding of blast resistance in rice VII. Gene analysis for the blast resistance of Indian native cultivar, Aus 373. Breed Sci., 47: 35.

Pan, Q., Wang, L., Ikehashi, H., et al., 1998. Identification of two new genes conferring resistance to rice blast in the Chinese native cultivar "Maowangu'. Plant Breeding., 117: 27-31.

Pan, Q.H., Hu, Z.D., Takatoshi, T., and Wang, L. 2003. Fine mapping of the blast resistance gene Pi15, linked to Pii, on rice chromosome 9. Acta Botanica Sinica, 45: 871-877.

Pan,Q., Wang, L., Ikehashi, H., and Tanisaka, T. 1996. Identification of a new blast resistance gene in the indica rice cultivar Kasalath using Japanese differential cultivars and isozyme markers. Phytopathology, 86 (10): 1071-1075.

Parker,D., Beckmann, M., Enot, P., Overy, D.P., Rios, Z.C., Gilbert, M., Draper, J. 2008. Rice blast infection of Brachypodium distachyon as a model system to study dynamic host/pathogen interactions, Nat. Protoc., 3 (3): 435-445.

Prasad, M.S., Kanthi, B.A., Balachandran, S. et al., 2009. Molecular mapping of rice blast resistance gene Pi-1 (t) in the elite indica variety Samba mahsuri. World J. Microbiol. Biotechnol., 25: 1765-1769.

Prasad, M.S., Viraktamath, B.C., Babu, V.R., and Madhav, M.S. 2015. Development and Identification of Novel Rice Blast
Resistant Sources and Their Characterization Using Molecular Markers. Rice Science, 22(6): 300-308.

Qu, S., Liu, G., Zhou, B., Bellizzi, M., Zeng, L., Dai, L., and Wang, G.L. 2006. The broadspectrum blast resistance gene $\mathrm{Pi} 9$ encodes a nucleotide binding siteleucine-rich repeat protein and is a member of a multigene family in rice. Genetics, 172(3): 1901-1914.

Ram, T., Majumder, N.D., Mishra, B., Ansari, M.M., Padmavathi, G. 2007. Introgression of broad-spectrum blast resistance gene(s) into cultivated rice (Oryza sativa ssp indica) from wild rice O. rufipogon. Curr Sci., 92: 225-230.

Rangel, P.N., Brondani, R.P.V., Rangel, P.H.N., and Brondani, C. 2008. Agronomic and molecular characterization of introgression lines from the interspecific cross Oryza sativa (BG90-2) $\times$ Oryza glumaepatula (RS-16). Genet. Mol. Res., 7(1): 184-195.

Rathour, R., Gaur, V.S., Kaushik, R.P., Chauhan, R.S. 2005. Oryza rufipogon A possible source of novel resistance specificities against rice blast (Magnaporthe grisea). Curr Sci., 89:1-4.

Sallaud, C., Lorieux, M., Roumen, E., Tharreau, D., Berruyer, R., Svestasrani, P., and Notteghem, J.L. 2003. Identification of five new blast resistance genes in the highly blast-resistant rice variety IR64 using a QTL mapping strategy, Theor. Appl. Genet., 106(5): 794-803.

Shang, J., Tao, Y., Chen, X. et al., 2009. Identification of a new rice blast resistance gene, Pid3, by genomewide comparison of paired nucleotide-binding site-leucine-rich repeat genes and their pseudogene alleles between the two sequenced rice genomes. Genetics, 182: 1303-1311.

Sharma, T., Madhav, M., Singh, B., Shanker, P., Jana, T., Dalal, V., and Upreti, H. 2005. High-resolution mapping, cloning and molecular characterization of the $\mathrm{Pi}$ kh gene of rice, which confers resistance 
to Magnaporthe grisea. Mol. Genet. Genomics., 274(6): 569-578.

Sharma, T., Rai, A., Gupta, S., Vijayan, J., Devanna, B., and Ray, S. 2012. Rice blast management through host-plant resistance: retrospect and prospects, Agric. Res., 1(1): 37-52.

Sharma, T.R., Chauhan, R.S., Singh, B.M., Paul, R., Sagar, V., and Rathore, R. 2002. RAPD and pathotype analysis of Magnaporthe grisea population from North-western Himalayan region of India. J. Phytopathol., 150: 649-656.

Shi, B., Zhang, J., Zheng, Y., et al., 2012. Identification of a new resistance gene Pi$\mathrm{Da}(\mathrm{t})$ from Dacca6 against rice blast fungus (Magnaporthe oryzae) in Jin23B background. Molecular Breeding, 30: 1089-1096.

Singh, A.K., Gopalakrishnan, S., Singh, V.P. et al., 2011. Marker assisted selection: a paradigm shift in Basmati breeding. Indian J. Genet., 71: 1-9.

Singh, V.K., Singh, A., Singh, S. et al., 2012. Incorporation of blast resistance into "PRR78", an elite Basmati rice restorer line, through marker assisted backcross breeding. Field Crops Res., 128: 8-16.

Sreewongchai, T., Toojinda, T., Thanintorn, N., Kosawang, C., Vanavichit, A., Tharreau, D., and Sirithunya, P. 2010. Development of elite indica rice lines with wide spectrum of resistance to Thai blast isolates by pyramiding multiple resistance QTLs. Plant Breeding, 129: 176-180.

Suh, J., Cho, Y., Won, Y., Ahn, E., Baek, M., Kim, M., Kim, B., and Jena, K. 2015. Plant Breed. Biotech., 3(4):333-345.

Sun, P., Liu, J., Wang, Y., et al., 2013. Molecular mapping of the blast resistance gene Pi49 in the durably resistant rice cultivar Mowanggu. Euphytica., 192: 4554.

Tabien, R., Li, Z., Paterson, A. et al., 2000. Mapping of four major rice blast resistance genes from 'Lemont' and 'Teqing' and evaluation of their combinatorial effect for field resistance. Theoret. Appl. Genet., 101: 1215-1225.
Tabien, R., Li, Z., Paterson, A. Marchetti, M., Stansel, J., and Pinson, S. 2002. Mapping QTLs for field resistance to the rice blast pathogen and evaluating their individual and combined utility in improved varieties, Theor. Appl. Genet. 105: 313324.

Tanweer. F A., Rafii. M.Y., Sijam. K., Rahim. H.A., Ahmed. F., and Latif. M.A. 2015. Current advance methods for the identification of blast resistance genes in rice. C.R. Biologies, 338: 321-334.

Terashima, T., Fukuoka, S., Saka, N., and Kudo, S. 2008. Mapping of a blast field resistance gene Pi39 (t) of elite rice strain Chubu 111. Plant Breeding, 127: 485-9.

Toojinda, T., Tragoonrung, S., Vanavichit, A., Siangliw, J.L., Pa-In, N., Jantaboon, J., Siangliw, M., and Fukai, S. 2005. Molecular breeding for rainfed lowland rice in the Mekong region. Plant Prod. Sci., 8(3): 330-333.

Wang, G.L., Mackill, D.J., Bonman, J.M., McCouch, S.R., Champoux, M.C., and Nelson, R.J. 1994. RFLP mapping of genes conferring complete and partial resistance to blast in a durably resistant rice cultivar. Genetics, 136 (4): 14211434.

Wang, J., Jia, Y., Wen, J., Liu, W., Liu, X., Li, L., and Ren, J. 2013. Identification of rice blast resistance genes using international monogenic differentials, Crop Prot., 45: 109-116.

Wang, Y., Wang, D., Deng, X., et al., 2012. Molecular mapping of the blast resistance genes Pi2-1 and Pi51 (t) in the durably resistant rice 'Tianjingyeshengdao'. Phytopathology, 102: 779-86.

Wang, Z., Jia, Y., Rutger, J., and Xia, Y. 2007. Rapid survey for presence of a blast resistance gene $\mathrm{Pi}$-ta in rice cultivars using the dominant DNA mar-kers derived from portions of the Pi-ta gene. Plant Breed., 126(1): 36-42.

Wang, Z.X., Yano, M., Yamanouchi, U., Iwamoto, M., Monna, L., Hayasaka, H., and Sasaki, T. 1999. The Pib gene for rice blast resistance belongs to the nucleotide 
binding and leucine-rich repeat class of plant disease resistance genes. Plant J., 19(1): 55-64.

Wen, S., Gao, B. 2012. Introgressing blastresistant gene Pi-9 (t) into elite rice restorer Luhui17 by marker-assisted selection. Rice Genomics Genet., 2(4): 31-36.

Wongsaprom, C., Sirithunya, P., Vanavichit, A., et al., (2010). Two introgressed quantitative trait loci confer a broadspectrum resistance to blast disease in the genetic background of the cultivar RD6 a Thai glutinous jasmine rice. Field Crops Res., 119: 245-51.

Wu, J.L., Fan, Y.Y., Li, D.B., Zheng, Leung, K.L., and Zhuang, H.J.Y. 2005. Genetic control of rice blast resistance in the durably resistant cultivar Gumei 2 against multiple isolates. Theor. Appl. Genet., 111(1): 50-56.

Wu, K., Martinez, C., Lentini, Z., Tohme, J., Chumley, F. Scolnik. and Valent, P.B. 1996. Cloning a blast resistance gene by chromosome walking, in: G.S. Khush (Ed.), Rice Genetics III. Proceedings of the Third International Rice Genetics Symposium, IRRI: International Rice Research Institute, Manila, Philippines. pp. 669-674.

Wu, K.S., and Tanksley, S.D. 1993. Abundance, polymorphism and genetic mapping of microsatellites in rice, $\mathrm{Mol}$. Gen. Genet., 241(1-2): 225-235.

Wu, Y., Bao, Y., Xie, L., et al., 2013. Fine mapping and identification of blast resistance gene Pi-hk1 in a broadspectrum resistant japonica rice landrace. Phytopathology, 103: 1162-1168.

Xiao, N., Wu, Y., Pan, C. et al., 2017. Improving of Rice Blast Resistances in Japonica by Pyramiding Major R Genes. Front. Plant Sci., 7: 1918.

Yuan, B., Zhai, C., Wang, W. et al., 2011. The Pik-p resistance to Magnaporthe oryzae in rice is mediated by a pair of closely linked CC-NBS-LRR genes. Theoret. Appl. Genet., 122: 1017-1028.
Zenbayashi, K., Ashizawa, T., Tani, T., and Koizumi, S. 2002. Mapping of the QTL, Theor. Appl. Genet., 104(4): 547-552.

Zenbayashi-Sawata, K., Ashizawa, T., and Koizumi, S. 2005. Pi34-AVRPi34: a new gene-for-gene interaction for partial resistance in rice to blast caused by Magnaporthe grisea. J. Gen. Plant Pathol., 71: 395-401.

Zhang, F.T., and Xie, J.K. 2014. Genes and QTLs resistant to biotic and abiotic stresses from wild rice and their applications in cultivar improvements. In: Yan W G, Bao J S. Rice: Germplasm, Genetics and Improvement. Croatia, European Union: InTech., DOI: $10.5772 / 56825$.

Zhou, B., Qu, S., Liu, G. et al., 2006. The eight amino-acid differences within three leucine-rich repeats between $\mathrm{Pi} 2$ and Piz- $\mathrm{t}$ resistance proteins determine the resistance specificity to Magnaporthe grisea. Molecular Plant-Microbe. Interact., 19: 1216-1228.

Zhou, J., Wang, J., Xu, J., et al., 2004. Identification and mapping of a rice blast resistance gene $\mathrm{Pi}-\mathrm{g}(\mathrm{t})$ in the cultivar Guangchangzhan. Plant Pathol., 53: 191196.

Zhu, M., Wang, L., and Pan, Q. 2004. Identification and characterization of a new blast resistance gene located on rice chromosome 1 through linkage and differential analyses. Phytopathology, 94: 515-519.

Zhu, X., Chen, S., Yang, J., et al., 2012. The identification of Pi50 (t), a new member of the rice blast resistance $\mathrm{Pi} 2 / \mathrm{Pi} 9$ multigene family. Theoret. Appl. Genet., 124: 1295-1304.

Zhu, X., Yang, Q., Yang, J., Lei, C., Wang, J., and Ling, Z. 2004.Differentiation ability of monogenic lines to Magnaporthe grisea in indica rice. Acta Phyto-pathol. Sin., 34(4): 361-368.

Zhu, Y.Y., Fang. H., Wang, Y.Y., Fan, J.X., Yang, S.S., Mew, T.M., and Mundt, C.C. 2005. Panicle blast and canopy moisture 
in rice cultivar mixtures, Phytopathology, 95: 433-438.

Zhuang, J.Y., Ma, W.B., Wu, J.L., Chai, R.Y., Lu, J., Fan, Y.Y., and Zheng, K.L. 2002.
Mapping of leaf and neck blast resistance genes with resistance gene analog, RAPD and RFLP in rice. Euphytica., 128(3): 363-370.

\section{How to cite this article:}

Ashim Debnath, Karma Landup Bhutia and Hage Sumpi. 2018. Mapping and Deployment of Blast Resistance Gene in Rice - A Work in Progress. Int.J.Curr.Microbiol.App.Sci. 7(05): 2073-2094. doi: https://doi.org/10.20546/ijcmas.2018.705.243 